\title{
Percutaneous Implantation of Autologous Bone Marrow Osteoprogenitor Cells as Treatment of Bone Avascular Necrosis Related to Sickle Cell Disease
}

\author{
Philippe Hernigou ${ }^{*}, 1$, Gilsasio Daltro ${ }^{2}$, Paolo Filippini ${ }^{1}$, Martin Mukisi Mukasa ${ }^{3}$ and \\ Olivier Manicom ${ }^{3}$ \\ ${ }^{I}$ Department of Orthopaedic Surgery, 51 Avenue du Maréchal de Lattre de Tassigny, 94010 cedex Créteil, France \\ ${ }^{2}$ Hospital Edgar Santos, University Federal of Bahia, Salvador, Brazil \\ ${ }^{3}$ Hôpital de Point à Pitre - Guadeloupe, France
}

\begin{abstract}
The treatment of bone a vascular necrosis is a big challenge considering the youthfulness of the patients involved by necrosis in sickle cell disease and the importance of the generated disability. A vascular osteonecrosis is an epiphysis pathology which could be treated by joint replacement with success, however, multiple surgical procedures are mostly necessary during the patient's life with a hazardous long term functional results. The treatment by autologous bone marrow grafting is an effective alternative which preserve the native joint. Using this mini-invasive high technology surgical treatment in early stages, a joint replacement could be avoided in many patients.
\end{abstract}

Keywords: Avascular osteonecrosis, marrow grafting, mesenchymal stem cell, bone regeneration.

\section{INTRODUCTION}

Sickle cell anemia, an autosomal-recessive disorder, is a hemolytic anemia characterized by abnormally shaped (sickled) red blood cells, which are removed from the circulation and destroyed at increased rates, leading to anemia [1-4]. Of greater clinical importance, the sickled RBCs cause vascular occlusion, which leads to tissue ischemia and infarction. Those who are homozygous for the sickle cell gene (hemoglobin SS) have a high risk of bone osteonecrosis due to microvascular occlusion in relation with the disturbance in the erythrocyte architecture, the polymerization of hemoglobin S (in a deoxygenated state) producing cells that are crescent- or sickle-shaped with decreased deformability; the decreased deformability results in greater risk for clotting in small vessels. The incidence of osteonecrosis is also high in patients with hemoglobin SC (compound heterozygotes for HbS- and HbC-producing alleles: SC) and in the various types of sickle-beta-thalassemia (SThal) population. So, patients with sickle cell disease often present with orthopaedic disease manifestations requiring surgical intervention, with the most common indications being osteonecrosis and osteomyelitis [5-9]. Customarily, patients with osteonecrosis of the femoral head (ONFH) have been treated nonsurgically. However, purely medical treatment will allow only few patients to live with their condition for one or two years. Usually, the patients are kept off weight-bearing on the affected side; however, this treatment principle has several limitations: the diseases frequently bilateral; it does not abolish the muscle tone around the joint, even when the patient is

*Address correspondence to this author at the Service de Chirurgie Orthopédique et Traumatologique, Hospital Henri Mondor, 51 avenue du Maréchal de Lattre de Tassigny, 94010 cedex Créteil, France; Tel: 00331 498126 01; Fax: 0033149812608 ;

E-mail: philippe.hernigou@wanadoo.fr lying down. The use of two elbow crutches (as a substitute for axillary crutches) does not provide the required complete weight relief; and even if crutches afford some protection, there is still the question of how long the patients should be kept off weight-bearing. Between the diagnosis of ONFH and the loss of femoral head sphericity, up to 4 or 5 years may elapse. Strictly speaking, the patients should be kept off weight-bearing for this entire period of time. Seeing that the patients are usually young and in the midst of their working lives, it would be futile to attempt such prolonged weight relief. It should also be borne in mind that if patients are kept on non-surgical treatment for a long period of time, eventual surgery may come too late, since the lesions will, by then, have progressed to a stage where femoral head preserving surgery can no longer help.

Very early in the course of the disease, core decompression [10] remains the most logical treatment modality, if one accepts that the condition is a compartment syndrome, with increased pressure inside the femoral head. Core decompression has been in use for a considerable time; the results reported by different authors vary no doubt because of different patient populations and different $\mathrm{ON}$ stages treated with decompression. However, while fundamental research and clinical studies have shown that dead bone may be revascularized by living bone, the reparative osteogenic potential is slight in ONFH: the number of bone progenitor cells in the uninvolved part of the femoral head and in the trochanteric region is less than in healthy subjects. It would, therefore, make sense not only to core, but to introduce new cells. This can be done by placing a tibial graft, a vascularized graft or cancellous bone into the coring tract. The same result may be produced more readily by harvesting bone marrow from the anterior iliac crests, concentrating the marrow thus obtained, and reinjecting it into the necrotic zones. 
Once the femoral head has lost its sphericity, core decompression will still afford pain relief, but will not be able efficaciously and lastingly to halt the gradual collapse of the weight-bearing zone. The important goal to achieve at this stage is the immobilization of the necrotic segment. A mobile segment will produce increased pressure in the femoral head, and may contribute to the progression of the necrosis. To this end, attempts have been made to use early reconstruction, with debridement of the necrotic zone and replacement of the dead bone with autologous bone reinforced with a vascularized fibular graft, to support the subchondral bone at risk of collapse. This is an attractive approach, which does, however, require the patient to be kept off weightbearing for a long period of time (3 - 6 months). The surgery involved is technically demanding; the postoperative management is quite cumbersome ( 3 - 6 months off weightbearing); often, both hips are affected; and the treatment may not work. This is why only few patients have been managed in this way.

Since the survival of the cartilage cells is ensured by their nutrition from the synovial fluid, the femoral head may be restored to sphericity by elevating the necrotic segment and keeping it in this restored position, by the injection of cement. In this approach, acrylic cement is used to give the femoral head its correct shape, and to delay the progression to OA which follows the deformation of the head. Cement injection has several advantages: it allows immediate weight-bearing; it provides immediate pain relief; and it does not interfere with the patient's work for an unduly long period of time. Also, conversion to a hip replacement is straightforward, should the pain recur. In such cases, femoral head resurfacing would undoubtedly be a suitable treatment option.

For femoral head preserving surgery, osteotomies of various kinds (valgus, varus, flexion, deflexion, rotational) have been used for a long time. These osteotomies are still difficult to perform. Also, they may require prolonged weight relief after surgery, and conversion to hip replacement in case of failure may be difficult.

The treatment by joint replacement is controversy because of the age of the patients involved and the number of complications observed in this disease. However, reconstruction and repair is usually incomplete after core decompression alone. One of the reasons of insufficient creeping substitution to achieve bone remodeling after osteonecrosis may be the small number of progenitor cells present in the osteonecrosis region in these patients [11]. In osteonecrotic hips, there is a decrease in osteogenic stem cells in the femoral head beneath the sequestrum and in the intertrochanteric region. This was confirmed by the extent of osteocyte death in the proximal femur seen in patients having total hip arthroplasty for osteonecrosis [12]. Avascular osteonecrosis treatment should therefore stimulate and influence bone remodeling by creeping substitution to preserve the integrity of the osteonecrotic zone. Using progenitor cells may be one means to achieving this. It seems sensible to not only use core decompression but also introduce new cells. This article includes a new approach to the conservative surgical management of patients with osteonecroses related to sickle cell disease. Autologous bone marrow transplantation was proposed for the treatment of osteonecrosis in 1990 with good results [13-15]. We report in this study our technique and clinical results with this treatment in sickle cell disease.

\section{GRAFTING WITH AUTOLOGOUS BONE MAR- ROW IN BONE AVASCULAR NECROSIS}

In clinical practice, autologous bone marrow is harvested from the iliac crest and transplanted to the site of bone avascular necrosis after concentration.

\subsection{Marrow Aspiration and Concentration}

Bone marrow is aspirated under general anesthesia from the anterior or posterior iliac crest. After deep insertion of a beveled needle $8 \mathrm{~cm}$ long and $1.5 \mathrm{~mm}$ in diameter into cancellous bone, the marrow is aspirated into $10 \mathrm{ml}$ syringe. $300 \mathrm{ml}$ of marrow is aspirated in small fractions to reduce the degree of dilution by peripheral blood. Several perforations into the iliac crest, using the same skin incision, are sometimes necessary to obtain this marrow volume. The marrow is pooled in plastic bags containing cell culture medium and anticoagulant solution (citric acid, sodium citrate and dextrose).

The marrow is first filtered to separate cellular aggregates and fat. It is then concentrated in a cell separator (Cobe 2991, Gambro BCT, Paris, France). A 5 minutes centrifugation at $400 \mathrm{~g}$ force the polynuclear cell layer, which is heavier because of its nuclei, to the periphery where it is collected and separated from the remainder of the marrow. The leukocyte layer is removed at a flow rate of $100 \mathrm{ml}$ per minute for 45 seconds. The red cells are found in the centre and are recovered with the plasma. All that remained is the mononuclear layer containing the stem cells. This centrifugation technique reduces a $300 \mathrm{ml}$ bone marrow aspirate to a $50 \mathrm{ml}$ of stem cells. The procedure is about 40 minutes long, the patients' remains under general anaesthesia during this time.

\subsection{Bone Marrow Grafting}

The concentrated marrow is injected through a percutaneous approach using a 3-mm diameter trocar (trocar of Mazabraud, Collin, France) in the centre of the necrosis. This is performed through the major tuberosity for avascular necrosis of the humeral head, through the greater trochanter for avascular necrosis of the femoral head, through the lateral or the medial condyle for avascular necrosis of the distal femur, or through an antero-medial approach for avascular necrosis of the proximal tibia. The position of the trocar is monitored with biplane fluoroscopy. 20 to $30 \mathrm{ml}$ of concentrated bone marrow is injected through the trocar directly in the necrosis zone. During injection, the pressure increase, but a normal pressure pattern is restored once the injection is finished. There is no joint immobilization after the surgery.

\section{ASPIRATED AND REINJECTED MARROW CHARACTERISTICS}

The number of nucleated cells obtained from bone marrow aspiration is estimated to be 16.4 millions cells per $\mathrm{mL}$ ( \pm 11.5$)$. In samples incubated in-vitro, the number of colony-forming units is on average $12.4 \pm 3.4$ per $10^{6}$ bone marrow nucleated cells. The differences between connective tissue progenitors harvested from various individual depend on many variables such as age, gender and local and systemic disease. There is particularly a significant difference in the number of colony-forming units obtained from the iliac 
crest according to the etiologic factors of the osteonecrosis. The quantity of medullar nuclear cells per $\mathrm{kg}$ of marrow can be calculated using a formula that takes into account blood dilution. In each $\mathrm{ml}$ of aspirate, it was estimated that medullar cells were represented by the difference between the nuclear cells count in the aspirate and that in peripheral blood, which is assessed during general anaesthesia. The number of nucleated cells of presumed medullar origin per $\mathrm{kg}$ is expressed as follows:

$\mathrm{N}\left(10^{8} / \mathrm{kg}\right)=(\mathrm{V} \times \mathrm{NP})-(\mathrm{V}-100) \times \mathrm{NS} / \mathrm{P}$

where $\mathrm{V}$, total volume of aspirate in $\mathrm{ml}$, including the harvesting medium; NP, nuclear cell count per $\mathrm{ml}$ in the collection bag; V-100, the exact volume of aspirate, after subtraction of the $100 \mathrm{ml}$ of harvesting medium; NS, the nuclear cell count per $\mathrm{ml}$ of peripheral blood drawn during the surgical procedure; and $\mathrm{P}$, patient's weight in kilograms.

Thus, for a total final volume of $400 \mathrm{ml}(300 \mathrm{ml}$ aspirate $+100 \mathrm{ml}$ medium) containing $16 \times 10^{6}$ nuclear cells per $\mathrm{ml}$, obtained from a $70 \mathrm{~kg}$ adult with a leukocyte count of $4 \times$ $10^{6}$ per $\mathrm{ml}$, it may be estimated that the medullar nuclear cell count is $7 \times 10^{7}$ per $\mathrm{kg}$.

\section{RESULTS}

This technique was developed in the Henri Mondor Hospital (Créteil, France) in 1990 and some patients have now a follow-up of 17 years. The clinical results of a prospective study of 189 symptomatic osteonecrotic hips in 116 patients treated with decompression and autologous bone marrow grafting were reported [15]. Among these patients, 38 had Sickle Cell Disease and these patients were followed up from 10 to 17 years. The mean age of the patients at the time of decompression and autologous bone marrow grafting was 29 years (range, 16-41 years) and the number of hips was 56. The aim of this paper is to compare the evolution of these patients with the natural course of the disease as reported by the authors in an other study [18].

The average total number of colony-forming units obtained from bone marrow aspiration was estimated to be $37 \times$ $10^{3}$ cells after culture of samples in vitro. After concentration (cell recovery: $84.3 \%$ ) the average total number of colonyforming units injected by hip was estimated to be $31 \times 10^{3}$ cells. Patients were operated on before collapse (24 at Stage I and 32 at Stage II). Patients were followed up from 10 to 17 years (mean 14 years). The outcome was determined by the changes in the Harris hip score [16], by progression in radiographic stages according to Steinberg et al. classification [17], and by the need for hip replacement. No complication was recorded during the anaesthesia. Patients who did not require total hip arthroplasty $(n=51)$ had a mean Harris hip score of 72 points preoperatively and 89 points postoperatively. Decompression and autologous bone marrow grafting decreased pain in all the patients postoperatively and delayed the progression of the disease to collapse during a period as long as 17 years for the patients with the longest follow-up and with an average period of 14 years for $87 \%$ of the hips (49 among 56 hips) of this series. Total hip arthroplasty was necessary in 5 hips that progressed to collapse.

The mean preoperative volume of the osteonecrosis was 26 cubic centimetres (minimum 12, maximum 30 cubic centimetres). The mean volume of the abnormal signal measured on MRI at the most recent follow-up (mean 10 years) was 12 cubic. This means a reduction in percentage from $32 \%$ to $16 \%$ when the volume of the osteonecrosis is related to the volume of the femoral head. Fifteen hips demonstrated total resolution of osteonecrosis on MRI. All had stage I osteonecrosis of the femoral head at the time of treatment with autologous bone marrow grafting. An abnormal signal persisting as sequelae was on T1 images an intralesional area of low intensity signal with a disappearance of the marginal band like pattern was present in the other hips operated at stage I.

\section{DISCUSSION}

Our experience with autologous bone marrow grafting in sickle cell disease was begun as early as 1990. Our results demonstrate that autologous bone marrow grafting is an effective treatment for early stages related to sickle cell disease, that the technique is safe in this population of patients, and that bone repair in osteonecrosis was observed.

Decompression and autologous bone marrow grafting decreased pain in all the patients postoperatively and delayed the progression of the disease to collapse during a period as long as 17 years for the patients with the longest follow-up and with an average period of ten years for $87 \%$ of the hips (49 among 56 hips) of this series. In the natural history of the disease stage progression occurred regardless of stage at the initial visit: among the patients of the historical series [18], thirty-two hips were seen with stage I at the initial visit, and forty-three hips were observed at stage II at the initial visit and among the seventy-five hips, sixty-five hips ( 87 percent) demonstrated collapse within five years after the diagnosis. In the actual series (with treatment by bone marrow grafting), only seven (12.5 per cent) among fifty-six hips demonstrated collapse at a follow-up of five years. The KaplanMeier curves, showed significant longer durations of survival before collapse for the 56 hips with autologous bone marrow grafting than for the 75 hips of the historical series without treatment $(\mathrm{p}<0.01)$.

The effectiveness of bone-marrow mononuclear cells may be related to the availability of stem cells endowed with osteogenic properties arising from an increase in the supply of such cells to the osteonecrotic zone through bone-marrow implantation [19-22]. Another explanation for the therapeutic effect of bone-marrow implantation is that injected marrow stromal cells secrete angiogenic cytokines, resulting in increased angiogenesis and subsequent improvement in osteogenesis.

In concluding patients with osteonecrosis related to SCD can be severely disabled by the status of their hip. Total hip arthroplasty (THA) remains for some of these patients the only surgical option according to the status of their hip when severe degenerative changes are present after collapse. However, because the results of reports of THA in SCD involve a higher complications rate and incidence of failure with revision than arthroplasty in osteonecrosis [23, 24] related to other conditions, it is important to know that other surgical options exist for early stages of this disease: core decompression and physical therapy, bone marrow transplantations, and cementoplasty. These treatments should be recommended at early stages of osteonecrosis to postpone the need for hip arthroplasty. 


\section{collapse progression}

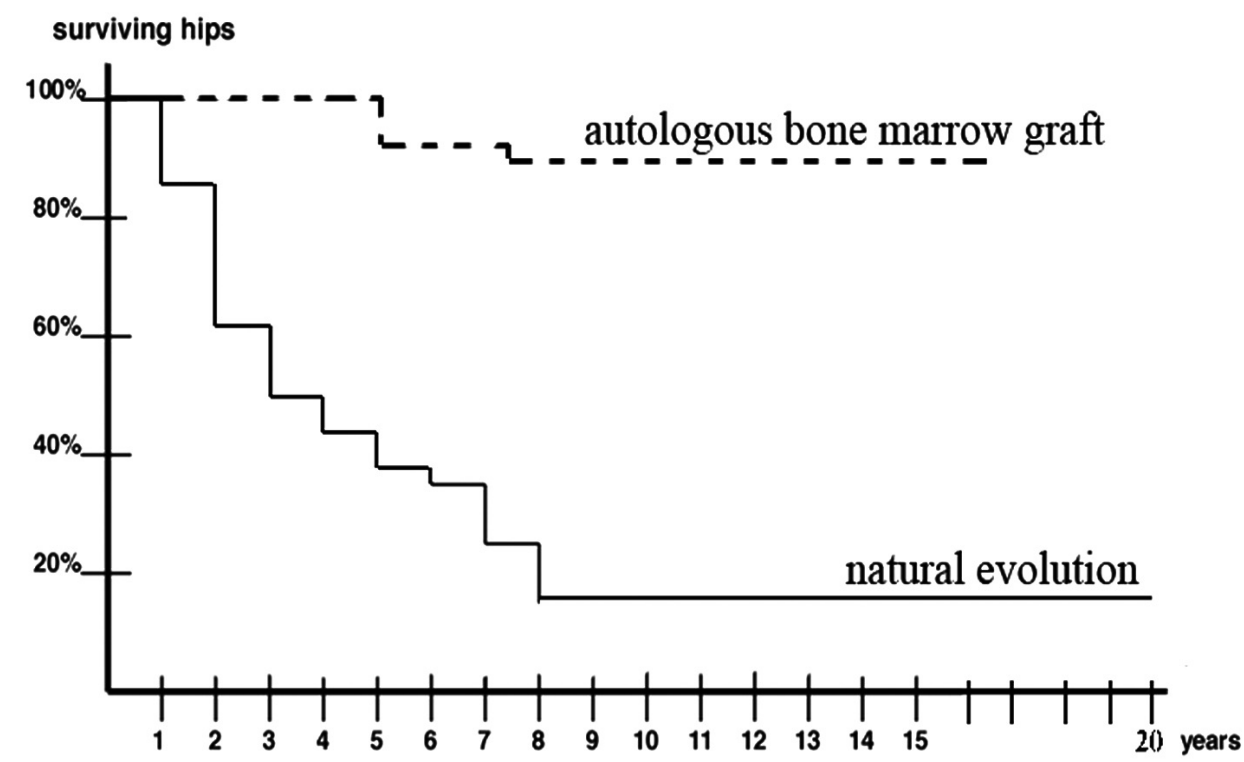

Fig. (1). Comparison of the natural evolution of hip osteonecrosis with the evolution after percutaneous implantation of bone marrow.

\section{REFERENCES}

[1] Ingram VM. Gene mutations in human haemoglobin: the chemical difference between normal and sickle cell haemoglobin. Nature 1957; 180: 326-28.

[2] Steinberg MH. Management of sickle cell disease. N Engl J Med 1999; 340: 1021-30.

[3] Steinberg MH, Nagel RL, Higgs D, Ed. Disorders of Hemoglobin: Genetics, Pathophysiology, and Clinical Management. New York, NY; Cambridge University Press; 2001.

[4] Stuart MJ, Nagel RL. Sickle-cell disease. Lancet 2004; 364: 134360

[5] Huo MH, Friedlaender GE, Marsh JS. Orthopaedic manifestations of sickle-cell disease. Yale J Biol Med 1990; 63: 195-207.

[6] Diggs LW. Bone and joint lesions in sickle-cell disease. Clin Orthop Relat Res 1967; 52: 119-43.

[7] Milner PF, Kraus AP, Sebes JI, et al. Sickle Cell Disease as a cause of osteonecrosis of the femoral head: N Engl J Med 1991; 325: 1476-81.

[8] Hernigou Ph, Galacteros F, Bachir D, Goutallier D. Deformities of the hip in adults who have sickle-cell disease and had avascular necrosis in childhood. J Bone Joint Surg 1991; 73 A: 81-92.

[9] Almeida A, Roberts I. Bone involvement in sickle cell disease. $\mathrm{Br} \mathrm{J}$ Haematol 2005; 129: 482-90.

[10] Lieberman JR. Core decompression for osteonecrosis of the hip. Clin Orthop Relat Res 2004; (418): 29-33.

[11] Hernigou P, Beaujean F, Lambotte JC. Decrease in the mesenchymal stem-cell pool in the proximal femur in corticosteroid-induced osteonecrosis. J Bone Joint Surg Br 1999; 81: 349-55.

[12] Calder P, Revell P, Pearse MF. The extent of osteocyte death in osteonecrosis of the femoral head. J Bone Joint Surg Br 1998; 80(suppl 1): 84

[13] Hernigou P. Autologous bone marrow grafting of avascular osteonecrosis before collapse. Rev Rhum (Engl Ed) 1995; 62: 65051.
[14] Hernigou P, Bernaudin F, Reinert P, Kuentz M, Vernant JP. Bone marrow transplantation in Sickle Cell Disease; effect on osteonecrosis. J Bone Joint Surg 1997; 79-A: 1726-30.

[15] Hernigou P, Beaujean F. Treatment of osteonecrosis with autologous bone marrow grafting. Clin Orthop Relat Res 2002; 405: 1423.

[16] Harris WH. Traumatic arthritis of the hip after dislocation and acetabular fractures: treatment by mold arthroplasty. An end-result study using a new method of result evaluation. J Bone Joint Surg Am 1969; 51: 737-55.

[17] Steinberg ME, Hayken GD, Steinberg DR. A quantitative system for staging avascular necrosis. J Bone Joint Surg Br 1995; 77: 34 41.

[18] Hernigou P, Bachir D, Galacteros F. The natural history of symptomatic osteonecrosis in adults with sickle celle disease. J Bone Joint Surg 2003; 85-A: 500-04.

[19] Haynesworth SE, Goshima J, Goldberg VM, Caplan AI. Characterization of cells with osteogenic potential from human marrow. Bone 1992; 13: 81-8.

[20] Bruder SP, Jaiswal N, Ricalton NS, Mosca JD, Kraus KH, Kadiyala $\mathrm{S}$. Mesenchymal stem cells in osteobiology and applied bone regeneration. Clin Orthop Relat Res 1998; (355 Suppl): S247-56.

[21] Bruder SP, Kurth AA, Shea M, Hayes WC, Jaiswal N, Kadiyala S Bone regeneration by implantation of purified, culture-expanded human mesenchymal stem cells. J Orthop Res 1998; 16: 155-62.

[22] Muschler GF, Nakamoto C, Griffith LG. Engineering principles of clinical cell-based tissue engineering. J Bone Joint Surg Am 2004; 86-A: 1541-58.

23] Bishop AR, Roberson JR, Eckman JR, Fleming LL. Total hip arthroplasty in patients who have sickle-cell hemoglobinopathy. J Bone Joint Surg Am 1988; 70: 853-55.

[24] Clarke HJ, Jinnah RH, Brooker AF, Michaelson JD. Total replacement of the hip for avascular necrosis in sickle cell disease. J Bone Joint Surg Br 1989; 71: 465-70. 